\title{
UM PERFIL DA PESQUISA EM ENSINO DE AS- TRONOMIA NO BRASIL A PARTIR DA ANÁLISE DE PERIÓDICOS DE ENSINO DE CIÊNCIAS ${ }^{+*}$
}

\author{
Jayme Marrone Júnior \\ Mestrando do Curso de Mestrado em Ensino de Ciências \\ e Educação Matemática - UEL \\ Rute Helena Trevisan \\ Departamento de Física - UEL \\ Londrina - PR
}

\section{Resumo}

Este artigo é o resultado de uma dissertação de mestrado que tem por objetivo descrever o perfil da pesquisa em Ensino de Astronomia no Brasil, por meio da análise dos periódicos de Ensino de Ciências, publicados nos últimos 20 anos. O trabalho é constituído de duas partes: uma quantitativa, cujos dados foram coletados pela seleção de 1772 artigos publicados em periódicos de circulação nacional, e a segunda parte, que corresponde à análise e interpretação de 38 artigos publicados no Caderno Brasileiro de Ensino de Física, onde buscamos elaborar uma visão da área a partir das publicações de seus pesquisadores. Utilizamos a Análise de Conteúdo de Laurence Bardin como referencial teórico e como técnica de coleta/análise dos dados na primeira parte e, ainda, o conceito de transposição didática de Chevallard na segunda parte, como forma de avaliação dos padrões encontrados nos textos destes periódicos que permitiram reconhecer a visão dos autores sobre a área analisada. Encontramos, no final da análise, uma área ainda em construção, mas com características bem definidas no que tan-

${ }^{+}$A profile of the research in Astronomy Teaching in Brazil from the periodic review of the Sciences Teaching

* Recebido: setembro de 2008. Aceito: setembro de 2009. 
ge aos problemas de pesquisa encontrados, à forma como são divulgados e à iniciativa dos pesquisadores em transformar o Ensino de Astronomia em potencial recurso didático.

Palavras-Chave: Ensino de Astronomia; análise de conteúdo; periódicos de ensino de ciências.

\begin{abstract}
The article is the result of my master's degree dissertation that is to describe the profile of the research in Astronomy Teaching in Brazil, through the newspapers of Science Teaching analysis that have been published in the last twenty years. The work is divided in two parts, a quantitative one, in which the data were collected by the analysis of 1772 articles published in newspapers of national circulation, and a second part that corresponds to an interpretation of a 38 published articles in the Caderno Brasileiro de Ensino de Física, where we tried to understand how it is described by researchers. As a theoretical referential, we used the Laurence Bardin's Content Analysis, and as a technique of data analysis/collect in the first part and yet the Chevallard's Didactic Transposition Concept in the second part as a way to evaluate the patterns found in the texts of these newspapers that allowed us to recognize the author's view of the analyzed area. What we have found was an area that is still been built, but with very defined characteristics when the issue are the problems that were found, the way they are spread and the researcher's concern in transforming the Astronomy Teaching in a potential didactic resource.
\end{abstract}

Keywords: Teaching of Astronomy; content analysis; newspapers of teaching of sciences.

\title{
I. Introdução
}

Este artigo é resultado de nosso trabalho de investigação, cuja intenção foi pesquisar a relação entre a produção acadêmica e a divulgação científica na área de 
Astronomia e Ensino de Astronomia. O foco da pesquisa foi a produção de textos em revistas da área, indexadas ou não.

Como mostram os trabalhos anteriores de Bretones e Megid Neto (2003) e Maciel (1996), a preocupação com o Ensino de Astronomia a partir dos anos 90 nos levou a questionar se realmente ocorreu, nos trabalhos publicados, uma inclinação direcionada à abordagem astronômica no Ensino de Física nos últimos anos. Entendemos que essa abordagem seja, muitas vezes, a alternativa mais promissora que um professor adota para motivar seus alunos.

Não é raro encontrar opiniões que colocam a Astronomia como um capítulo do Ensino de Física, muitas vezes relegado ao esquecimento, quando muito abordado numa aula de Gravitação Universal ou nas Leis de Kepler, apenas como: "[...] e antigamente era assim que se pensava". Talvez a confusão esteja no fato de que utilizar uma abordagem histórica no Ensino de Física passa, obviamente, pela história da Astronomia e é apenas nesse contexto que nos parece adequado estudálas sem distinção.

Oscar T Matsuura (1998), em uma conferência na Expo Astro, apresenta um trabalho sobre divulgação da Astronomia onde critica a necessidade de incluir a Astronomia como disciplina autônoma. Atualmente, nem seus conteúdos precisam constar explicitamente nos programas curriculares. Para ele, o caminho mais rápido para a divulgação é colocar à disposição dos professores do Ensino Básico um material didático adequado e de acesso facilitado.

Comungamos com a ideia de Matsuura e entendemos que as publicações, sob forma de artigos, dos pesquisadores na área de Ensino de Astronomia, podem ser usadas como recurso didático no aprimoramento desses professores, já que sua disponibilidade via Internet os torna extremamente acessíveis.

$\mathrm{Na}$ tentativa de organizar e selecionar esse material, percebemos a riqueza de informações que tínhamos em mãos e decidimos ajustar nossas lentes na possibilidade de descrever a área de Ensino de Astronomia por meio desses artigos, uma vez que a produção bibliográfica de uma área possui muita força em termos de construção de sua identidade (PASSOS et al, 2005).

Para tal análise, escolhemos as revistas sugeridas pela Associação Brasileira em Pesquisa em Educação em Ciências (Abrapec), devido à sua representatividade perante a comunidade científica.

São elas: Revista Abrapec, Ciência \& Educação, Investigações em Ensino de Ciências, Caderno Brasileiro de Ensino de Física, Revista Brasileira de Ensino de Física, Revista Latino-Americana de Educação em Astronomia, Revista Ensaio, A Física na Escola e Ciência \& Ensino. 
Nossa inquietação se resumiu então na seguinte problemática:

Qual o retrato da pesquisa em Ensino de Astronomia no Brasil, revelada a partir da análise dos artigos publicados nos periódicos de Ensino de Ciências?

Assim, dividimos o trabalho em duas etapas:

A primeira se refere a uma abordagem quantitativa, buscando encontrar dados que possibilitem entender volume de trabalhos relacionados com a área, mas sem entrar no âmbito da análise das condições de produção dos mesmos. O intuito foi responder se a comunidade científica tem utilizado o Ensino de Astronomia como tema de pesquisa. Com essa visão geral, selecionamos o Caderno Brasileiro de Ensino de Física (CBEF) como representante desses periódicos, pelo número de artigos (38) e pelo tempo de existência (desde 1984). Esta primeira etapa foi importante para que pudéssemos avaliar o volume de trabalhos publicados sobre o tema Astronomia e Ensino de Astronomia nesses periódicos e compararmos com os artigos referentes à Física e ao Ensino de Física.

A segunda etapa proporcionou uma análise qualitativa dos artigos produzindo um meta-texto do material investigado fazendo emergir deste os elementos necessários à descrição da área de pesquisa em Ensino de Astronomia a partir da interpretação dos trabalhos de seus pesquisadores.

Foi nessa segunda parte que se revelaram mais fortemente as características da área Ensino de Astronomia no Brasil, vista sob a lente da Análise de Conteúdo de sua produção bibliográfica.

\section{Referencial teórico}

Usamos como ferramenta as técnicas de Análise de Conteúdo (AC) que Laurence Bardin (1988) aplicou na investigação psicossociológica e no estudo das comunicações de massas.

De forma pontual, nossa pesquisa também buscou elucidar, nos artigos de ensino de Astronomia, a relação entre o saber oriundo da pesquisa, sua veiculação e o saber docente inserido na formação continuada dos professores, embora esse não tenha sido nosso foco, acreditamos que os dados levantados possam ser utilizados em outros trabalhos que se desdobrem na relação dos saberes. Na análise da veiculação do saber por meio da produção escrita nos periódicos, usamos o trabalho de Roque Moraes (2003) no que tange à comunicação e aprendizagem pela escrita, o qual afirma que um artigo revela não só a posição de quem o escreve, mas também a tendência do pensamento da comunidade onde o autor se encontra inserido. Embora neste trabalho o autor se refira ao processo de escrita e reescrita 
como uma forma de aprimorar o processo de aprendizagem em um ambiente escolar, encontramos a mesma posição, que se refere à compreensão de um texto como representação social, nos trabalhos de Silvia H. B. Cardoso (2003).

Por último, e não menos importante, tomamos alguns conceitos da Transposição Didática, utilizados inicialmente por Chevallard e Joshua (1982) e Chevallard (1991) na didática francesa, necessários para entendermos a forma como os pesquisadores produzem seus artigos.

A Transposição Didática não implica como poderíamos pensar ingenuamente, apenas uma simplificação de conteúdos presentes no contexto da ciência sábia. Essa concepção ingênua de como se produz conhecimento escolar é, ainda hoje, o grande obstáculo epistemológico a ser enfrentado nas discussões envolvendo as práticas escolares, pois, para muitos, a educação científica básica é resultado de um processo de seleção e de simplificação de conteúdos. No Ensino de Astronomia, em particular, isso ocorreria pela diminuição da profundidade conceitual e do formalismo matemático das teorias. Mais do que uma terminologia adequada à descrição dos fenômenos astronômicos, a Transposição Didática permite entender e analisar a definição de saberes de pesquisa, sujeitos a influências externas e internas à dimensão educacional propriamente dita. As múltiplas influências se devem ao fato de que todo saber de pesquisa se insere em um contexto específico, que é a comunidade científica em questão.

\section{Escolha do material para análise}

Trabalhamos com as revistas relacionadas no site da Associação Brasileira de Pesquisadores em Ensino de Ciências (ABRAPEC).

Na pré-análise, utilizamos algumas regras na escolha dos documentos, conforme sugestão de Laurence Bardin (1988). Dessa forma, temos:

a) A exaustividade

Significa esgotar a totalidade da comunicação, o que, para nós, representa trabalhar com todas as revistas relacionadas pela ABRAPEC, ou seja, foram pesquisados nove dos principais periódicos de circulação nacional.

Procuramos atender à classificação observando termos referentes à Astronomia, conforme Quadro 01.

b) A representatividade

Encontramos em 91 artigos, de um universo de 1772, alguma referência à astronomia, seja no título, palavras-chave ou resumo, elegendo assim esses 91 
como representantes da produção acadêmica entre 09 revistas de Educação e Ensino de Ciências que circulam em território nacional nos últimos 22 anos.

Devido ao grande número de artigos, acabamos por escolher uma única revista - o Caderno Brasileiro de Ensino de Física - por ter o maior número de artigos (38) e também por ter mais de 20 anos de publicação. Acreditamos que tenha sido uma boa representação do universo a ser analisado.

c) A pertinência

Os documentos são os periódicos de divulgação ou revistas didáticopedagógicas e formam o objeto da pesquisa.

d) A exclusividade

A escolha dos artigos obedeceu a apenas uma categoria; os 38 artigos sobre Astronomia do Caderno Brasileiro de Ensino de Física que possuem em seu título ou nas palavras-chave uma referência clara ao tema.

\begin{tabular}{|l|c|l|c|}
\hline Palavra & Frequência & Palavra & Frequência \\
\hline Astronomia & 8 & Einstein & 1 \\
\hline Ensino de astronomia & 3 & Aristóteles & 1 \\
\hline Força /atração gravitacional & 5 & Kepler & 2 \\
\hline Gravitação & 7 & Thyco Brahe & 1 \\
\hline Gravidade & 2 & Copérnico & 2 \\
\hline Cosmogonia & 1 & Lua & 1 \\
\hline Cosmologia & 6 & Terra/Céu & 8 \\
\hline Universo & 3 & Estrela(s) & 1 \\
\hline Sol & 6 & Eclipse(s) & 5 \\
\hline Etnoastronomia & 1 & Espaço & 2 \\
\hline Órbitas & 1 & Meteorologia & 1 \\
\hline Movimento de precessão & 3 & Gnômon & 1 \\
\hline Planeta(s) & 2 & Marés & 2 \\
\hline Cometa(s) & 2 & Atmosfera & 1 \\
\hline Supernova & 1 & Estações do Ano & 2 \\
\hline Lunetas/telescópios & 1 & Luz & 3 \\
\hline Galileu & 3 & Radioastronomia & 2 \\
\hline
\end{tabular}

Quadro 01 - Frequência de aparecimento de algumas palavras nos títulos ou palavras-chave dos artigos. 
Como resultado desta pré-análise, tivemos:

Revista Abrapec - Qualis A nacional (Área 46 da CAPES)

104 artigos, de 2001 a 2005, dos quais 2 referentes à Astronomia.

Revista Brasileira de Ensino de Física - Qualis B nacional (Área 46)

608 artigos, de 1996 a 2005, dos quais 26 selecionados.

Caderno Brasileiro de Ensino de Física - Qualis A nacional (Ensino de Ciências)

552 artigos, dos quais 38 referentes à Astronomia, de 1984 a 2005.

\section{Revista Física na Escola}

93 artigos, dos quais 11 referem-se à Astronomia, de 2001 a 2005.

Ciência e Educação - Qualis B internacional (Ensino de Ciências)

118 artigos, dos quais 3 selecionados, de 1998 a 2004.

Investigação em Ensino de Ciências - Qualis A internacional (Área 46)

122 artigos, dos quais 1 é referente à Astronomia, de 1996 a 2005.

Revista Ensaio - Qualis B nacional (Área 46)

134 artigos e nenhum se refere à Astronomia.

\section{Revista Ciência e Ensino}

31 artigos, dos quais 3 referentes à Astronomia, de 1997 a 1999.

A próxima fase da pré-análise foi a formulação dos objetivos, que fizemos por meio de uma leitura flutuante (leitura sem a pretensão direta de análise) do material selecionado. Todas as fases que apresentamos para a análise são sugeridas no trabalho de Laurence Bardin em sua Análise de Conteúdo, inclusive a chamada leitura flutuante. O trabalho de apropriação do texto ocorreu de forma gradual com várias idas e vindas entre o artigo e nossas concepções a respeito do discurso dos pesquisadores, até o momento em que pudemos definir os contornos das unidades de registro.

A partir da análise dos artigos, agrupamos as unidades de registro dividindo o trabalho em duas partes. A primeira, quantitativa, disponibilizou os dados desde a distribuição dos artigos em cada revista, passando pela leitura dos 91 artigos até a escolha dos 38 artigos do CBEF selecionados. A segunda apresentou os dados e a análise qualitativa de acordo com as unidades citadas interpretando a forma como os pesquisadores entendem a área de Ensino de Astronomia. 


\section{Apresentação dos dados}

Iniciamos a apresentação dos dados com uma tabela oriunda de um processo de leitura dos 1772 títulos da revistas anteriormente citadas. Essa leitura ocorreu de forma transversal; por vezes o artigo foi lido na íntegra, pois o título ou o resumo não expressavam ideia exata do assunto abordado, em outros apenas o título e/ou resumo eram suficientes para a tomada de dados. Foram selecionados os artigos que possuíam palavras conforme o Quadro 1.

A Tabela 1 abaixo descreve o percentual de artigos referentes à Astronomia em relação ao total de artigos publicados da revista em questão.

Tabela 1 - Percentual de artigos referentes à Astronomia nas revistas analisadas.

\begin{tabular}{|c|c|c|c|c|}
\hline REVISTAS & PERÍODO & $\begin{array}{c}\text { ARTIGOS } \\
\text { PUBLICADOS }\end{array}$ & $\begin{array}{c}\text { REFERENTES } \\
\underset{\text { À }}{\text { ASTRONOMIA }}\end{array}$ & $\begin{array}{c}\text { PERCEN- } \\
\text { TUAL } \\
\%\end{array}$ \\
\hline Abrapec & 2001 a 2005 & 104 & 2 & 2 \\
\hline $\begin{array}{l}\text { Revista Bra- } \\
\text { sileira } \\
\text { de Ensino de } \\
\text { Física }\end{array}$ & 1996 a 2005 & 608 & 26 & 4,2 \\
\hline $\begin{array}{c}\text { Caderno } \\
\text { Brasileiro } \\
\text { de Ensino de } \\
\text { Física }\end{array}$ & 1984 a 2005 & 552 & 38 & 6,8 \\
\hline RELEA & 2004 a 2005 & 10 & 9 & 90 \\
\hline $\begin{array}{l}\text { Física na } \\
\text { Escola }\end{array}$ & 2001 a 2005 & 93 & 11 & 11,8 \\
\hline $\begin{array}{l}\text { Ciência e } \\
\text { Educação }\end{array}$ & 1998 a 2004 & 118 & 3 & 2,5 \\
\hline $\begin{array}{c}\text { Investigação } \\
\text { em } \\
\text { Ensino de } \\
\text { Ciências }\end{array}$ & $\begin{array}{l}1996 \mathrm{a} \\
2005 .\end{array}$ & 122 & 1 & 0,8 \\
\hline Ensaio & 1999 a 2005 & 134 & 0 & 0 \\
\hline $\begin{array}{c}\text { Ciência e } \\
\text { Ensino }\end{array}$ & 1997 a 2005 & 31 & 3 & 9,6 \\
\hline $\begin{array}{c}\text { Total de } \\
\text { artigos }\end{array}$ & $\begin{array}{c}\text { De } 1984 \text { a } \\
2005\end{array}$ & 1772 & 91 & 5,2 \\
\hline
\end{tabular}

Observamos que apenas $5.2 \%$ do total das publicações analisadas trazem alguma referência à Astronomia. Se compararmos com a pesquisa em Ensino de Física em uma só revista, que é aquela que escolhemos para a análise, obtivemos 
139 artigos de um total de 552, ou seja, cerca de $25 \%$ do total. Para a pesquisa em Astronomia, na mesma revista, temos 38 de 552, próximo de 6,8\%. O baixo índice no tema Astronomia, se refere possivelmente ao espaço de tempo muito curto do início das publicações na área do Ensino. A pesquisa também ressalta a dificuldade de distinguir o que seja um trabalho sobre Ensino de Física e trabalho em Ensino de Astronomia. Na falta de um referencial que nos permita distinguir cada um, entenderemos que aqueles artigos que abordam conceitos físicos, com efetiva aplicação a fenômenos astronômicos (eclipses, fases da lua, atividade solar, etc.), serão localizados em Ensino de Astronomia; os demais em Ensino de Física, ou seja, consideraremos a Astronomia como uma área de aplicação da Física, tal qual a Engenharia.

A Tabela 2 abaixo foi criada a partir de nossa compreensão do que classificaremos como técnico e de divulgação. Para nós, todo artigo publicado que faz do formalismo matemático a essência do documento, ou seja, aquele no qual a ausência dessa linguagem compromete o seu entendimento, será considerado um texto técnico.

Tabela 02 - Classificação dos artigos: técnico e de divulgação.

\begin{tabular}{lccc}
\hline Período & Técnico & Divulgação & Sub-Total \\
\hline 1985 a 89 & 10 & 02 & 12 \\
1990 a 94 & 07 & 03 & 10 \\
1995 a 99 & 07 & 01 & 08 \\
2000 a 05 & 06 & 02 & 08 \\
Total & 30 & 08 & 38
\end{tabular}

Percebeu-se a preocupação da comunidade científica em tornar acessíveis os trabalhos publicados, o que compõe uma parte importante do perfil da área no que tange ao uso da Transposição Didática pelos pesquisadores quando se dispõem a divulgar seu trabalho. Mas como a comunidade realizou a transposição didática? Observamos que a maior parte da produção é direcionada sob forma de informação, conforme mostramos abaixo.

Na Tabela 03, descrevemos a classificação dos artigos levando em conta os objetivos, por período.

Tabela 03 - Objetivo dos artigos. 


\begin{tabular}{lccccc}
\hline Período & Informativo & Oficina & Reflexivo & Divulgação & Sub-total \\
\hline 1985 a 89 & 07 & 04 & 01 & 00 & 12 \\
1990 a 94 & 07 & 02 & 00 & 01 & 10 \\
1995 a 99 & 04 & 01 & 00 & 03 & 08 \\
2000 a 05 & 01 & 02 & 02 & 03 & 08 \\
Total & 19 & 09 & 03 & 07 & 38 \\
\hline
\end{tabular}

Observamos que $50 \%$ dos artigos possuem caráter apenas informativo. Esse resultado nos permite entender que os autores procuram capturar a atenção de uma faixa ampla da comunidade acadêmica e professores, visto que 24 artigos (64\% do material analisado) têm como característica as adequações realizadas para compor o saber a ensinar.

Ao buscar palavras-chave (citadas no Quadro 1), percebemos que a maioria dos artigos não as possui especificamente. Sendo assim, utilizamos o título do artigo como referencial para extrairmos tais palavras. Exemplo:

a) Em "Porque o Céu é azul", identificamos a palavra Céu.

b) Em "A deflexão da Luz pela gravidade e o eclipse de 1919", identificamos Deflexão, Luz, Gravidade e Eclipse.

$\mathrm{O}$ Quadro 02 resume as palavras-chave encontradas nos artigos das revistas relacionadas.

Percebemos que a revista com maior número de artigos sobre o tema é o CBEF e, analisando as palavras-chave de uma forma geral, identificamos que várias são comuns em todas as revistas que possuem artigos referentes à Astronomia. Justifica-se, assim, a escolha do CBEF como representante dessas revistas em nosso trabalho, atentando também ao fato do período de publicação deste periódico.

Desta forma, fizemos uma análise das palavras-chave apenas na revista escolhida e verificamos que a maior incidência das palavras: Universo, Terra, Sol, Cosmologia, e Gravitação nos artigos indicam o perfil dos trabalhos publicados e juntamente com as palavras Eclipse, Força, Física Aristotélica, Cometa, Lua, Luz, Livros didáticos e História da Ciência definem as linhas temáticas dos pesquisadores nesta área. Observamos três características dessa comunidade científica: a primeira nos mostra a necessidade dos pesquisadores em discorrer sobre fenômenos básicos da Astronomia, a segunda revela a força da abordagem histórico-filosófica presente nestes trabalhos, enquanto que a terceira reflete a preocupação da área em alfabetizar de forma correta e contextualizada nossos estudantes e professores acerca do tema Astronomia. 
Quadro 02 - Palavras-chave.

\begin{tabular}{ll}
\hline Revista & Palavras-chave \\
\hline Abrapec & Astronomia, Ciência, Forma da Terra, Concepções. \\
RBEF & Singularidades, Precessão, Órbitas, Gnômon, Marés, Sistema Terra-Lua, \\
& Planetas, Kepler, Gravitação, Einstein, Hubble, Universo, Céu, Sol, Meteo- \\
& rologia Espacial, Fases da Lua, Modelos Cosmológicos, Aceleração do \\
& Universo, Manchas Solares, Teoria Quântica, Cosmologia. \\
RELEA & Estações do Ano, Radioastronomia, Etnoastronomia, Astronomia Moderna, \\
& Terra e Céus, Ensino de Astronomia, Espaço, Modelo Sol-Tierra. \\
& Quantum, Planck, Expansão, Universo, Thyco Brahe, Espaço, Concepção, \\
& Eter, Kepler, Ensino, Órbita, Terra, Eclipses, Sol, Lua, Newton, Força \\
& Gravitacional, Cosmologia, Einstein. \\
I. E. C & História da Ciência, Gravitação, Estações do Ano. \\
Ciência & Força Gravitacional, Planeta, Terra. \\
e Ensino & Marés, Gravitação, Espaço. \\
& \\
& Aceleração da Gravidade, Astronomia, Big Bang, Céu, Cosmologia, Come- \\
& ta, Constelações, Concepções prévias, Construtivismo, Copérnico, Calor, \\
& Divulgação, Dia e Noite, Deflexão da luz, Estrelas, Esfera Celeste, Einstein, \\
& Estações do ano, Erros, Éter, Epiciclos, Equantes, Eclipse, Força, Física \\
& aristotélica, Filatelia, Formação continuada, Formação inicial, Formação \\
& de professores, Fóton, Galáxias, Galileu, Gravitação História da ciência, \\
& Historia da Astronomia, Homem, Kepler, Livro didático, Lentes, Luneta, \\
& Lua, Luz, Marés, Metafísica, Miragens gravitacionais, Meridiano magnéti- \\
& co, Modelos planetários, Movimento, Nuvens de Magalhães, Órbitas, Ob- \\
& servação, Paradigma, Planetas, Quasar, Radiação, Relatividade, Radioas- \\
& tronomia, Sol, Sistema Solar, Supernova, Saber, Sociedade, Terra, Tempo, \\
& Telescópios, Universo. \\
\hline &
\end{tabular}

Distribuímos, então, os trabalhos em três eixos temáticos:

Eixo 1 - Física aplicada à Astronomia

Trabalhos relacionados com conceitos físicos e sua aplicação na explicação de fenômenos astronômicos.

Eixo 2 - História e Filosofia aplicada à Astronomia

Trabalhos relacionados com a importância de descrever os conceitos astronômicos inseridos num contexto histórico e filosófico. 
Eixo 3 - Materiais didáticos e técnicas pedagógicas

Trabalhos referentes à produção e ao desenvolvimento de material didático, de divulgação de conceitos astronômicos, de análise de livro-texto, técnicas pedagógicas e concepção espontânea em sala de aula.

Esses eixos, no nosso entender, representam as principais maneiras que a comunidade tem utilizado para realizar a transposição didática da Astronomia.

Fizemos também um levantamento dos autores que publicaram nesta revista, conforme o Quadro 03, que representa um resumo desse levantamento.

Dos autores, destacamos oito com mais de dois artigos, dentre eles cinco continuam produzindo nos últimos 10 anos, são eles: João Batista Garcia Canalle, Rute Helena Trevisan, Cleiton Joni Benetti Lattari, Marcos César Danhoni Neves, Fernando Lang da Silveira.

Observamos também que, de forma pontual, os pesquisadores começam a se reunir em pequenos grupos criando veículos de divulgação de trabalhos da área, como o surgimento da revista RELEA em 2003, especializada no desenvolvimento de pesquisas na área de Ensino em Astronomia. $\mathrm{O}$ fato nos chega como um incentivo no que tange à produção de trabalhos nesta área.

Se observarmos o Gráfico 01, conseguiremos traçar um perfil quantitativo da produção de artigos referentes à Astronomia no CBEF por ano.

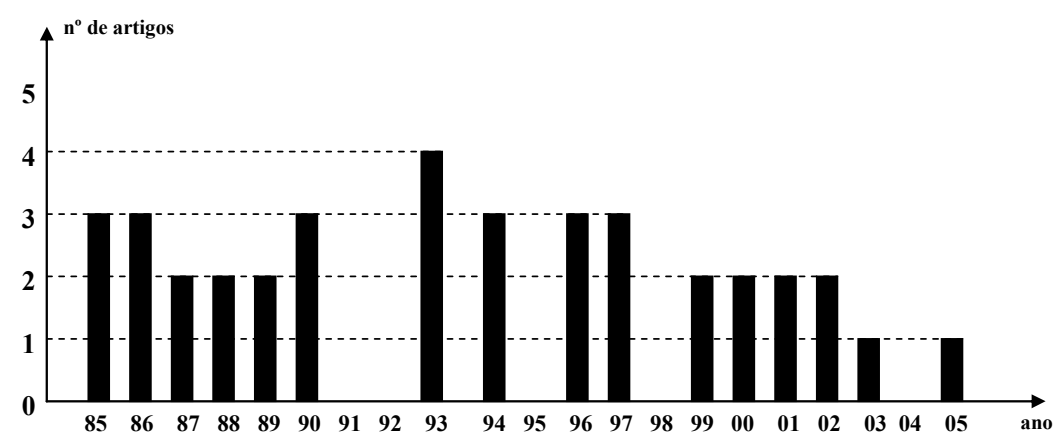

Gráfico 01 - Disposição do número de artigos por ano de publicação.

Ao colocarmos em blocos de 5 anos, observaremos melhor a evolução da produção dos pesquisadores.

Alertamos ao fato de que a produção de artigos na área vem diminuindo, talvez porque a comunidade sinta que essa fase da produção acadêmica utilizando a transposição dos saberes esteja se esgotando. 
Quadro 03 - Autor: quantidade / ano de publicação.

\begin{tabular}{|lc|l|}
\hline Autor / Quantidade & & Ano de publicação \\
\hline João Batista Garcia Canalle & 05 & $1994 / 97 / 97 / 99 / 2005$ \\
\hline Silvia Helena Becker Livi & 04 & $1987 / 87 / 90 / 93$ \\
\hline Rute Helena Trevisan & 03 & $1997 / 97 / 2001$ \\
\hline Cleiton Joni Benetti Lattari & 03 & $1997 / 97 / 2001$ \\
\hline F. F. de Souza Cruz & 02 & $1985 / 85$ \\
\hline José Maria Filardo Bassalo & 02 & $1990 / 90$ \\
\hline Marcos César Danhoni Neves & 02 & $2000 / 00$ \\
\hline Fernando Lang da Silveira & 02 & $2002 / 03$ \\
\hline Luiz Fernando Fava & 01 & 1985 \\
\hline Plínio Fasolo & 01 & 1986 \\
\hline Santos Diez Arribas & 01 & 1986 \\
\hline Flavio Renato Ramos de Lima & 01 & 1986 \\
\hline César de Oliveira Lopes & 01 & 1988 \\
\hline Arden Zylbersztajn & 01 & 1989 \\
\hline Ana Maria Afonso Goldfare & 01 & 1989 \\
\hline Virginia Mello Alves & 01 & 1993 \\
\hline Mauricio Pietrocola de Oliveira & 01 & 1993 \\
\hline Cláudio A. Perottoni & 01 & 1993 \\
\hline Wilson Lopes & 01 & 1994 \\
\hline Roberto de Andrade Martins & 01 & 1994 \\
\hline Augusto Damineli Neto & 01 & 1996 \\
\hline Luiz O. Q. Peduzzi & 01 & 1996 \\
\hline Pedro W. Lamberti & 01 & 1996 \\
\hline Júlio César Penereiro & 01 & 1997 \\
\hline Elder Sales Teixeira & 01 & 1999 \\
\hline Olival Freire Jr. & 01 & 1999 \\
\hline João Batista Siqueira Harres & 01 & 2001 \\
\hline Alexandre Medeiros & 01 & 2002 \\
\hline Maria Amélia Monteiro & 01 & 2002 \\
\hline Adelino Carlos Ferreira de Souza & 01 & 2005 \\
\hline & & \\
\hline
\end{tabular}




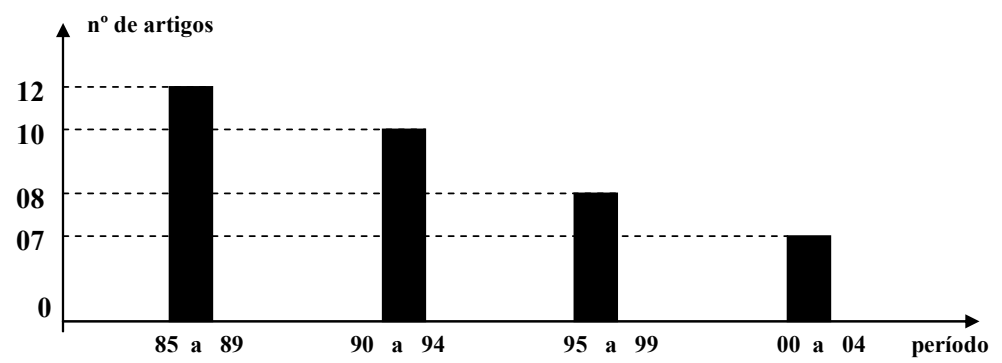

Gráfico 02 - Número de artigos por blocos de 5 anos.

A Tabela 04 mostra, em valores percentuais, a distribuição da utilização dos itens que definem a estrutura do artigo por período.

Tabela 04 - Distribuição da utilização dos itens que definem a estrutura do artigo por período.

\begin{tabular}{|c|c|c|c|c|c|c|c|}
\hline Período & $\begin{array}{c}\text { Resu- } \\
\text { mo } \\
\mathbf{( \% )}\end{array}$ & $\begin{array}{c}\text { Palavras- } \\
\text { chave } \\
\mathbf{( \% )}\end{array}$ & $\begin{array}{c}\text { Intro- } \\
\text { dução } \\
(\mathbf{\%})\end{array}$ & $\begin{array}{c}\text { Proble- } \\
\mathbf{m a} \\
\mathbf{( \% )}\end{array}$ & $\begin{array}{c}\text { Metodo- } \\
\text { logia } \\
\mathbf{( \% ) ~}\end{array}$ & $\begin{array}{c}\text { Referen- } \\
\text { cial } \\
\mathbf{( \% ) ~})\end{array}$ & $\begin{array}{c}\text { Conside- } \\
\text { rações } \\
\text { finais } \\
\mathbf{( \% )}\end{array}$ \\
\hline $1985-1989$ & 0 & 0 & 17 & 42 & 8 & 8 & 17 \\
\hline $1990-1994$ & 70 & 0 & 70 & 50 & 10 & 30 & 50 \\
\hline $1995-1999$ & 88 & 0 & 88 & 75 & 38 & 13 & 50 \\
\hline $2000-2004$ & 88 & 50 & 88 & 100 & 38 & 63 & 63 \\
\hline
\end{tabular}

Ao analisarmos a evolução da estrutura dos artigos (resumo, palavraschave, introdução, problema, metodologia, referencial teórico e considerações finais), percebemos a crescente preocupação dos pesquisadores em produzir artigos dentro de um padrão de organização, mesmo não contendo de forma explícita os itens acima descritos. Essa preocupação em parte se deve à exigência dos órgãos responsáveis pela divulgação em normalizar esse veículo e as datas de algumas normas coincidem com nossa análise.

Nossa pesquisa mostrou que dentro dos 91 artigos, aqueles publicados antes de 2000 não possuem a estrutura de artigo científico. No entanto, hoje é difícil encontrar algum que não esteja no formato adequado.

Conforme a análise abaixo, observamos a preocupação com outras formas de linguagem como gráficos, tabelas, figuras e descrevemos: 
Figuras - 27 (71\%) dos artigos fazem uso deste artifício.

Tabelas $-11(29 \%)$ dos artigos.

Gráficos $-5(13 \%)$ dos artigos.

Fórmulas $-14(37 \%)$ dos artigos.

Identificamos que $33(87 \%)$ artigos da amostra trazem a bibliografia, o que indica a preocupação do autor em oferecer ao leitor uma base confiável de informações, ancorando seu trabalho em referenciais reconhecidos.

Com relação à metodologia utilizada na produção do trabalho, apenas 9 (24\%) artigos relatam a mesma.

As considerações finais estão presentes em 17 (45\%) artigos.

Analisando a acessibilidade dos artigos, identificamos que 55\% (21) destes encontram-se disponíveis on-line. O período de 1988 a 1996 não apresenta artigos disponíveis na rede.

Com relação à distribuição por instituição, temos a Universidade Federal de Santa Catarina e a Universidade Federal do Rio Grande do Sul como aquelas que mais produziram artigos (veja no Quadro 04).

Quadro 04 - Instituição / n ${ }^{0}$ Artigos/ Estado

\begin{tabular}{|l|c|l|l|l|l|}
\hline Instituição & $\mathrm{N}^{\mathrm{o}}$ de artigos & Estado & UNIV-GUARULHOS & 01 & SP \\
\hline UFSC & 07 & $\mathrm{SC}$ & UNICAMP-SP & 01 & SP \\
\hline PUC-RGS & 01 & $\mathrm{RS}$ & IAG-SP & 01 & SP \\
\hline ICEG-RGS & 01 & $\mathrm{RS}$ & UNC & 01 & ARG \\
\hline UFRGS & 07 & $\mathrm{RS}$ & UEL & 03 & PR \\
\hline UFRJ & 03 & RJ & UEFS & 01 & BA \\
\hline UERJ & 01 & RJ & UEM & 02 & PR \\
\hline CENDOTEC & 01 & SP & FEMA & 01 & SP \\
\hline PUC-SP & 02 & SP & UNIVATES-RGS & 01 & RS \\
\hline UFPA & 03 & PA & UFRP & 01 & PE \\
\hline UCS-RGS & 01 & RS & USP-SP & 01 & SP \\
\hline
\end{tabular}

Observamos que mais de $89 \%$ dos artigos são produzidos pelas regiões Sul e Sudeste do país, o que significa um número muito elevado para uma revista de circulação nacional, mesmo levando em consideração sua localização. Uma pergunta que fica para outros trabalhos é: Por que mais da metade (64\%) das pesquisas são realizadas no sul do país?

Cad. Bras. Ens. Fís., v. 26, n. 3: p.547-574, dez. 2009. 
Quadro 05 - Estado / n de artigos.

\begin{tabular}{|l|c|}
\hline Estado & $\mathrm{N}^{\mathrm{o}}$ de artigos \\
\hline Rio Grande do Sul & 11 \\
\hline Santa Catarina & 7 \\
\hline São Paulo & 5 \\
\hline Paraná & 5 \\
\hline Rio de Janeiro & 4 \\
\hline Pará & 3 \\
\hline Pernambuco & 1 \\
\hline
\end{tabular}

Ao final de nossa análise quantitativa, chamamos a atenção para o padrão dos assuntos abordados nesse conjunto de revistas, admitindo serem categorizados nos 3 eixos temáticos, por nós elaborados:

- Física aplicada à Astronomia

- História e Filosofia aplicada à Astronomia

- Materiais didáticos e técnicas pedagógicas.

Esta categorização dos objetos de pesquisa permitiu-nos eleger o $\mathrm{CBEF}$ como representante da produção científica da área, a ponto de traçarmos o perfil da Pesquisa em Ensino de Astronomia por meio de uma análise qualitativa de seus artigos, justificando, assim, a importância desta análise prévia.

Além disso, constatamos o crescente número de trabalhos produzidos dentro de uma formatação de divulgação, fazendo com que a área se coloque à disposição das exigências da comunidade científica, revelando sua capacidade de adequação às normas da mesma.

Com relação aos conteúdos abordados, a Tabela 05 mostra a grande contribuição da História da Astronomia na produção acadêmica da área que, em conjunto com a explicação de fenômenos astronômicos, representa mais de $60 \%$ da produção científica nesta revista, nos últimos 20 anos.

Observamos que a História da Astronomia tem se mantido regular, o que significa que, independente do período, essa é uma preocupação constante da área.

Já a explicação de fenômenos astronômicos vem diminuindo, conforme constatado a partir da análise do gráfico 04 .

Podemos interpretar esse gráfico como sendo um indicador de que os pesquisadores vêm perdendo o interesse pela transposição dos saberes. 
Tabela 5 - Relação de conteúdos

\begin{tabular}{|lll|}
\hline Conteúdo & $\begin{array}{l}\text { Quantida- } \\
\text { de }\end{array}$ & $\begin{array}{l}\text { Percentual } \\
(\%)\end{array}$ \\
\hline História da Astronomia & 12 & 32 \\
\hline Explicação de fenômenos & 11 & 29 \\
\hline Oficina & 05 & 12 \\
\hline Formação de professores & 03 & 8 \\
\hline Produção e análise de material & 03 & 8 \\
\hline Ensino de Astronomia & 02 & 5 \\
\hline Concepções Prévias & 01 & 3 \\
\hline Demonstrações algébricas & 01 & 3 \\
\hline Total & 38 & 100 \\
\hline
\end{tabular}

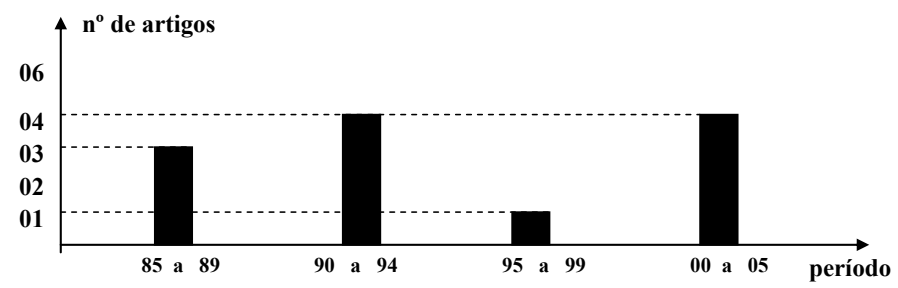

Gráfico 03 - Representa o número de artigos referentes à Historia da Astronomia por periodo.

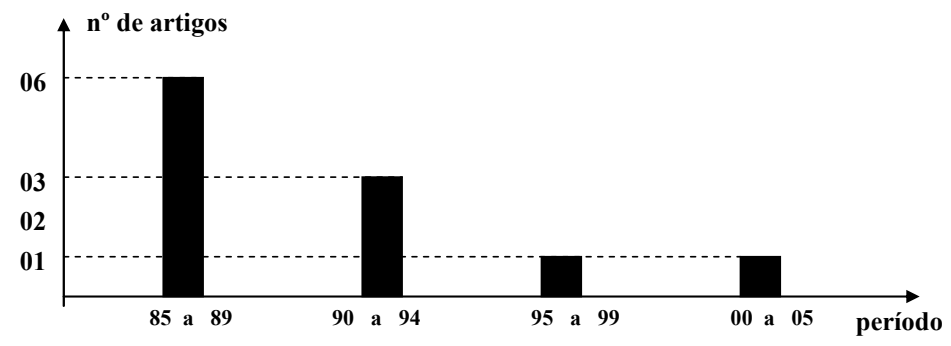

Gráfico 04 - Representa o número de artigos que se referem à explicação de fenômenos astronômicos por período. 


\section{Análise Qualitativa}

Iniciamos a segunda parte do nosso trabalho, que é a análise qualitativa dos artigos, visando entender, por meio da produção bibliográfica, as características da área de Ensino de Astronomia que os pesquisadores deixam transparecer em suas publicações.

Para isso, partimos de alguns problemas específicos de pesquisa.

A partir da análise do conteúdo desses artigos, o que é o Ensino de Astronomia para esses pesquisadores?

Quais os problemas levantados pela área nesses 20 anos?

Que referenciais teóricos foram utilizados?

A quais resultados de pesquisa que os artigos chegaram e o que eles dizem?

Apresentaremos inicialmente a análise geral dos 38 artigos, a fim de facilitar a compreensão; depois, analisaremos cada problema especificamente e, por fim, nas considerações finais, acreditamos poder descrever um pouco os atributos dessa área de pesquisa.

No Quadro 06, temos um fragmento do exemplo da análise:

1 - No campo artigo, aparece o número, o autor e o ano de publicação.

2 - Nas palavras-chave, temos uma classificação das características da pesquisa.

3 - Nos referenciais teóricos, além dos nomes, há uma referência ao conceito(s) utilizado(s) no artigo.

4 - No campo problema, buscamos identificar o que motivou o autor a escrever o artigo e também colocamos o tipo de conteúdo de acordo com a legenda:

4.1 - Explicar fenômenos astronômicos: EFA

4.2 - Conceitos físicos associados a fenômenos astronômicos: CFAFA

4.3 - Divulgação de fenômenos astronômicos: DFA

4.4 - Produção de oficinas: $\mathrm{PO}$

4.5 - História da Astronomia como recurso didático: HA

4.6 - Cosmologia e as origens do Universo: $\mathrm{COU}$

4.7 - Análise do conteúdo de astronomia em livros didáticos: ACLD

4.8 - Concepções prévias de estudantes e professores: $\mathrm{CP}$

5 - Nos resultados de pesquisa, buscamos captar a contribuição que o artigo promove para o leitor.

Notamos que nem sempre o artigo possui um problema de pesquisa, mesmo assim tentamos identificar aquilo que mais se aproxima de um problema. 
Quadro 06 - Problemas e resultados.

\begin{tabular}{|c|c|c|c|c|}
\hline $\begin{array}{l}\text { ARTI- } \\
\text { GOS }\end{array}$ & $\begin{array}{l}\text { PALAVRAS- } \\
\text { CHAVE }\end{array}$ & $\begin{array}{c}\text { REFERENCI- } \\
\text { AIS }\end{array}$ & PROBLEMA & RESULTADOS \\
\hline $\begin{array}{c}01 \\
1985 \\
\text { Fava }\end{array}$ & $\begin{array}{l}\text { Céu Azul } \\
\text { Pesquisa em } \\
\text { Ensino de } \\
\text { Física }\end{array}$ & $\begin{array}{c}\text { Ondulatória e } \\
\text { Óptica. } \\
\text { Goldemberg J, } \\
\text { Sears F.W, } \\
\text { Tipler P. A. }\end{array}$ & $\begin{array}{c}\text { Explicar o porquê } \\
\text { do azul do céu } \\
\text { EFA }\end{array}$ & $\begin{array}{c}\text { A cor azulada do } \\
\text { céu se deve à } \\
\text { presença da } \\
\text { atmosfera e, caso } \\
\text { esta não existisse, } \\
\text { o céu seria de dia } \\
\text { tão negro quanto } \\
\text { a noite. }\end{array}$ \\
\hline $\begin{array}{c}2 \\
1985 \\
\text { Cruz }\end{array}$ & $\begin{array}{c}\text { Força, História } \\
\text { da Ciência, } \\
\text { Cosmologia, } \\
\text { Física Aristoté- } \\
\text { lica. } \\
\text { Pesquisa em } \\
\text { Ensino de } \\
\text { Física }\end{array}$ & $\begin{array}{c}\text { Zylbersztjn, A, } \\
\text { Jammer M, } \\
\text { Collingwood } \\
\text { R.G, Chatelet F, } \\
\text { Padonani U. } \\
\text { História da } \\
\text { ciência. }\end{array}$ & $\begin{array}{c}\text { Mostrar a evolução } \\
\text { do conceito de força } \\
\text { na ciência grega } \\
\text { para justificar o } \\
\text { estudo da história } \\
\text { da ciência como } \\
\text { instrumento } \\
\text { didático. }\end{array}$ & $\begin{array}{c}\text { O artigo passa } \\
\text { rapidamente pelo } \\
\text { conceito de força } \\
\text { nos filósofos } \\
\text { gregos e repousa } \\
\text { sua atenção na } \\
\text { física aristotélica. } \\
\text { Mostra algumas } \\
\text { contradições, mas } \\
\text { principalmente } \\
\text { retrata a força } \\
\text { desta teoria } \\
\text { transformada em } \\
\text { dogmas pela Igreja. }\end{array}$ \\
\hline $\begin{array}{c}3 \\
1985 \\
\text { Cruz }\end{array}$ & $\begin{array}{c}\text { Força, História } \\
\text { da Ciência, } \\
\text { Cosmologia, } \\
\text { Física Aristoté- } \\
\text { lica. } \\
\text { Pesquisa em } \\
\text { Ensino de } \\
\text { Física }\end{array}$ & $\begin{array}{c}\text { Arthur Koestler, } \\
\text { Santo Agostinho, } \\
\text { São Tomás de } \\
\text { Aquino, Aristóte- } \\
\text { les, Roger Bacon, } \\
\text { João Philoponus, } \\
\text { Koyré A, Jam- } \\
\text { mer, Chatelet, } \\
\text { Collingwood } \\
\text { História da } \\
\text { ciência. }\end{array}$ & $\begin{array}{c}\text { Discutir o conceito } \\
\text { de força agora na } \\
\text { idade media, rela- } \\
\text { cionada à ação à } \\
\text { distância } \\
\text { HA }\end{array}$ & $\begin{array}{c}\text { É uma continuação do } \\
\text { artigo anterior, retra- } \\
\text { tando a forma como o } \\
\text { conceito aristotélico } \\
\text { de força na idade } \\
\text { média foi criticado e } \\
\text { se desenvolvendo com } \\
\text { outros pensadores, } \\
\text { como Buridan e } \\
\text { Kepler. }\end{array}$ \\
\hline
\end{tabular}

Usaremos o conjunto de palavras-chave para caracterizar o que a comunidade de pesquisadores entende por Ensino de Astronomia. Na impossibilidade de encontrar em todos os artigos essas palavras-chave, valer-nos-emos então de nosso contato com os 1772 artigos para atribuí-las àqueles que não possuem tais elemen- 
tos. O Quadro 07 representa a ocorrência do conjunto de palavras-chave que conseguimos detectar nos 38 artigos analisados.

Quadro 07 - Incidência das palavras.

\begin{tabular}{|c|c|c|c|}
\hline Palavra & Incidência & Palavra & Incidência \\
\hline Aceleração da Gravidade & 2 & História da ciência & 3 \\
\hline Astronomia & 2 & História da Astronomia & 1 \\
\hline Big bang & 2 & Homem & 1 \\
\hline Céu & 2 & Kepler & 1 \\
\hline Cosmologia & 5 & Livro didático & 3 \\
\hline Cometa & 3 & Lentes & 1 \\
\hline Constelações & 1 & Luneta & 1 \\
\hline Concepções prévias & 1 & Lua & 3 \\
\hline Construtivismo & 1 & Luz & 3 \\
\hline Copérnico & 2 & Marés & 1 \\
\hline Calor & 2 & Metafísica & 1 \\
\hline Divulgação & 1 & Miragens gravitacionais & 1 \\
\hline Dia e Noite & 1 & Meridiano magnético & 1 \\
\hline Deflexão da luz & 1 & Modelos planetários & 1 \\
\hline Estrelas & 1 & Movimento & 1 \\
\hline Esfera celeste & 1 & Nuvens de Magalhães & 1 \\
\hline Einstein & 1 & Órbitas & 2 \\
\hline Estações do ano & 1 & Observação & 2 \\
\hline Erros & 2 & $\begin{array}{l}\text { Paradigma } \\
\end{array}$ & 2 \\
\hline Éter & 1 & Planetas & 2 \\
\hline Epiciclos & 1 & Quasar & 1 \\
\hline Equantes & 1 & Radiação & 1 \\
\hline Eclipse & 3 & Relatividade & 1 \\
\hline Força & 3 & Radioastronomia & 1 \\
\hline Física aristotélica & 3 & Sol & 5 \\
\hline Filatelia & 1 & Sistema Solar & 1 \\
\hline
\end{tabular}




\begin{tabular}{||l|l|l||l||}
\hline \hline Formação continuada & 1 & Supernova & 1 \\
\hline \hline Formação inicial & 1 & Saber & 1 \\
\hline \hline Formação de professores & 1 & Sociedade & 1 \\
\hline \hline Fóton & 1 & Terra & 5 \\
\hline Galáxias & 1 & Tempo & 1 \\
\hline Galileu & 2 & Telescópios & 1 \\
\hline \hline Gravitação & 4 & Universo & 6 \\
\hline
\end{tabular}

Ao analisar as palavras-chave, entendemos quais são os interesses de pesquisa para a área: Universo, Terra, Sol, Cosmologia, Gravitação, ou seja, focados na curiosidade do ser humano em compreender os fenômenos astronômicos que nos rodeiam. Com relação à análise dos resultados dos artigos ou, poderíamos dizer, à análise do que os artigos falam, percebemos uma tendência dos autores em divulgar o conhecimento de forma abrangente. Ajustando nossa lente para o material como um conjunto único de trabalhos, entendemos que os problemas de pesquisa da área estão, de certa forma, voltados a uma tentativa de popularização da Astronomia, fazendo com que o tema se torne acessível aos professores, inclusive com a perspectiva de reeducá-los, visto que existe uma já comprovada deficiência na formação astronômica da maioria desses professores. Essa afirmação só é possível se verificarmos que a grande maioria dos trabalhos se refere à explicação, conceituação e divulgação de fenômenos astronômicos, sem falar nos questionamentos cosmogônicos que sem dúvida nenhuma fazem parte da curiosidade de nossos estudantes.

A preocupação em aperfeiçoar essa tarefa por meio de oficinas e de fiscalizar os meios de divulgação através da análise de livros-texto só ratifica nossa visão.

É nesse momento que nos deparamos com uma postura comum entre os autores, que é a de transpor seus saberes, o que nos remete ao conceito da Transposição Didática e sua prática revelada nas publicações dos pesquisadores.

A abordagem histórica adotada em grande parte dos artigos analisados revela a importância da regra três da Transposição Didática e ratifica o fato de sucumbirmos a ela nossas expectativas de análise, a fim de traçar o perfil da área.

Por fim, a análise qualitativa dos artigos aponta para um perfil da área de Pesquisa em Ensino de Astronomia, construída sob os seguintes argumentos: 
Os objetos de pesquisa abordados se identificam com fenômenos astronômicos que representariam o desejo do homem em conhecer o Universo.

Os artigos são colocados numa via de mão dupla entre a Física aplicada à Astronomia e a Astronomia aplicada ao Ensino de Física.

A comunidade de pesquisadores reconhece a importância da história da ciência na construção do conhecimento acerca dos fenômenos astronômicos.

A divulgação da evolução das visões de mundo descrita em vários artigos revela a necessidade dos autores de transmitir a noção de que a aprendizagem dos conceitos astronômicos leva o indivíduo a manter uma postura de questionamento frente aos paradigmas atuais, ou seja, conceitos definitivos e verdades absolutas não são atributos científicos.

O uso da transposição dos saberes indica a abertura que os autores promovem no intuito de contribuir com a área que se revela ainda em construção e que, portanto, permite um trânsito de trabalhos mais abrangentes do que, por exemplo, a Pesquisa em Ensino de Física. A consequência direta dessa constatação é a ausência, em muitos artigos, de um problema específico de pesquisa.

Mesmo admitindo uma determinada flexibilidade nos temas abordados, percebemos certa tendência dos trabalhos publicados a se agrupar nos eixos temáticos:

a - Física aplicada à Astronomia

b - História e Filosofia aplicada à Astronomia

c - Desenvolvimento, divulgação e controle de materiais didáticos e técnicas pedagógicas.

De acordo com a distribuição de conteúdo exposta no capítulo anterior, percebemos que a abordagem histórica na explicação de fenômenos astronômicos e sua divulgação é a grande sustentação dos trabalhos da área.

Ainda referente ao conteúdo, observamos uma baixa variação no número de trabalhos relacionados à história da astronomia, em contrapartida, temos uma redução de trabalhos explicando fenômenos astronômicos na ultima década, o que nos mostra a tendência da área em inicialmente solidificar sua base históricofilosófica e, a partir desta, produzir conhecimento novo.

Não é uma característica da área distinguir trabalhos em Ensino de Astronomia e em Astronomia.

A análise do material aponta para uma comunhão entre o Ensino de Física e a Astronomia.

A área se apresenta flexível no que tange às mudanças no formato de divulgação dos artigos. 
O grande número de artigos publicados com linguagem acessível (não formal) busca atingir o maior número de pessoas e mostra a preocupação dos pesquisadores em disseminar seus trabalhos para, no futuro, poder assentar as bases epistemológicas das pesquisas objetivando uma posterior consolidação da área.

Longe de impormos nossa visão da Pesquisa em Ensino de Astronomia, mas confiantes em nossos referenciais adotados para a análise, acreditamos que, com essa descrição, possamos fomentar questionamentos e discussões, no intuito de contribuir para a consolidação dessa área de pesquisa.

\section{Considerações finais}

Na verdade, iniciamos nossa pesquisa com a intenção de identificar, analisando a produção de artigos científicos em periódicos de Ensino de Ciências, a situação da pesquisa em Ensino de Astronomia no Brasil. Para isso, partimos de algumas hipóteses e fizemos algumas imposições de forma quase pretensiosa, como a própria definição do que seja um artigo de Ensino de Astronomia. Entendemos que essa atitude foi necessária para iniciarmos o trabalho. No entanto, no decorrer da análise percebemos que o material (38 artigos) é muito mais rico do que imaginávamos, e que nossa lente só conseguia mostrar uma parte. No momento em que chegamos ao final de nossa análise, percebemos que seria necessário ajustar nosso foco e deixar que o material se apresentasse, pois estes artigos representam estatisticamente uma produção de 20 anos.

Entendemos que a produção deste material pode, de forma estatística, representar a pesquisa em Ensino de Astronomia no Brasil. Um artigo que tenha como tema a História da Astronomia é um artigo de Ensino de Astronomia, pois mostra a evolução de um pensamento e da forma como um fenômeno astronômico foi visto, sua concepção em vários momentos da história e, dessa forma, indica caminhos e estratégias que podem ser tomadas em sala de aula. Da mesma maneira, uma oficina sobre tamanho real dos planetas está inserida em Ensino de Astronomia, ou a demonstração algébrica da força gravitacional, bem como a explicação sobre um fenômeno astronômico pode ser usada em sala de aula. Face ao observado, estes artigos nos mostram que conscientemente ou não os pesquisadores delinearam a pesquisa em Ensino de Astronomia com suas próprias publicações.

Fazendo uma análise sobre as palavras-chave, observamos que a maior incidência das palavras: Universo, Terra, Sol, Cosmologia, e Gravitação nos artigos indicam o perfil dos trabalhos publicados e, juntamente com as palavras Eclipse, Força, Física Aristotélica, Cometa, Lua, Luz, Livros didáticos e História da 
Ciência, definem a linha de pesquisa dos pesquisadores nesta área. Percebemos três características desta comunidade científica: a primeira nos mostra a necessidade dos pesquisadores em discorrer sobre fenômenos básicos da Astronomia, a segunda revela a força da abordagem histórico-filosófica presente nesses trabalhos e a terceira reflete a preocupação da área em alfabetizar de forma correta e contextualizada nossos estudantes acerca do tema Astronomia.

Dessa forma, distribuímos os trabalhos em três eixos temáticos:

Eixo 1 - Física aplicada à Astronomia

Trabalhos relacionados com conceitos Físicos e sua aplicação na explicação de fenômenos astronômicos.

Eixo 2 - História e Filosofia aplicada à Astronomia

Trabalhos relacionados com a importância de descrever os conceitos astronômicos inseridos num contexto histórico e filosófico.

Eixo 3 - Materiais didáticos e técnicas pedagógicas

Trabalhos referentes à produção e ao desenvolvimento de material didático, de divulgação de conceitos astronômicos, de análise de livro-texto, técnicas pedagógicas e concepção espontânea em sala de aula.

Se continuarmos esta linha de raciocínio, verifica-se que os referenciais adotados correspondem aos eixos temáticos acima descritos, salientando que, em cada um deles podemos eleger os mais reconhecidos:

Eixo 1 - A. Einstein; I. Newton; R. Feynman; R. Serway; G. E. Hubble; M. Planck; P. Kaufmann; Louis de Broglie; S. Weinberg.

Eixo 2 - T. Kuhn; A. Koyré; I. B. Cohen; A. Zylberstajn; A. Koestler; J. Kepler; G. Galilei; N. Copérnico; C. Ptolomeu; Aristóteles.

Eixo 3 - A. Zylbersztjn; R. H. Trevisan; W.J. Maciel; J. B. G. Canalle; C. J. B. Latari.

Ajustando nosso foco para o material como um conjunto único de trabalhos, entendemos que os problemas de pesquisa da área estão, de certa forma, voltados a uma tentativa de popularização da Astronomia, fazendo com que o tema se torne acessível aos professores, inclusive com a perspectiva de reeducá-los, visto que existe uma já comprovada deficiência na formação astronômica da maioria desses professores (LANGHI, 2004; LEITE, 2002; LIMA, 2006; PUZZO, 2005; QUEIROZ, 2008). Essa afirmação só é possível se verificarmos que a grande maioria dos trabalhos se refere à explicação, conceituação e divulgação de fenômenos astronômicos, sem falar nos questionamentos cosmogônicos, os quais, sem dúvida nenhuma, fazem parte da curiosidade de nossos estudantes. 
A preocupação em aperfeiçoar esta tarefa por meio de oficinas e de fiscalizar os meios de divulgação através da análise de livros-texto, só ratifica nossa visão.

Percebemos ainda, pela análise dos problemas, que aparece um grande número de trabalhos envolvendo conceitos físicos, o que reflete a ideia de uma linha ainda muito tênue entre o Ensino de Física e o Ensino de Astronomia. Ousamos até dizer que a área não tem, a priori, a preocupação em fazer esta distinção.

Observamos também que a abordagem histórica é presença marcante nos problemas de pesquisa que a área tem trabalhado, já que os artigos referentes ao tema circulam pela comunidade desde o surgimento da revista analisada.

Ao interpretar os resultados dos trabalhos, identificamos uma tendência da área em se preocupar com a alfabetização da sociedade com relação à Astronomia. Em uma análise global, parece-nos que a mesma reconhece a fragilidade dos conceitos astronômicos que circulam entre professores e estudantes e produz trabalhos que, investidos de uma abordagem histórico-filosófica, permitem a disseminação dos conceitos astronômicos numa linguagem acessível buscando retomar, por meio da Astronomia, a curiosidade do homem sobre o conhecimento físico da natureza que o cerca.

Entendemos que nosso trabalho pode contribuir para que se possam identificar esses elementos quantitativos e qualitativos que envolveram a pesquisa em Ensino de Astronomia no Brasil nestes últimos anos. Mas, considerando que a área do Ensino de Ciências engloba integralmente o Ensino de Astronomia, apesar de mais amadurecida, ainda nos perguntamos: "Pensando no presente estudo, julgamos pertinente procurar analisar o imaginário dos próprios pesquisadores da área a respeito de questões como: Existe uma área de educação em ciências no País? A que se deve o início da pesquisa em ensino de ciências no Brasil? Que fatores foram determinantes para a constituição dessa área? Quais são suas características? Como os pesquisadores da área caracterizam a pesquisa em ensino de ciências? Que fatores os levaram a escolher essa área como atividade de pesquisa acadêmica? Como veem a contribuição dos resultados da pesquisa na formação de professores de ciências? E na sala de aula?" (NARDI; ALMEIDA, 2007), vemos que o tema Ensino de Astronomia, está seguindo seu caminho, do mesmo modo que o fizeram as outras áreas relacionadas à Educação e ao Ensino no Brasil. 


\section{Referências}

BARDIN, L. Análise de Conteúdo. Lisboa: Edições 70, 1988.

BRETONES, P. S.; MEGID NETO, J. Tendências de Teses e Dissertações sobre

Ensino de Astronomia no Brasil. In: REUNIÃO ANUAL DA SOCIEDADE ASTRONÔMICA BRASILEIRA, XXIX, 2003, São Pedro. Boletim da Sociedade Astronômica Brasileira, v. 23, n. 1, p. 7, 2003.

CARDoso, S. H. B. Discurso e Ensino. Belo Horizonte: Autêntica/FALE, 2003.

CHEVALLARD, Y.; JOHSUA, M-A. Un exemple d'analyse de la transposition didactique - La notion de distance. Recherches en Didactique des mathematiques, v. 3, n. 2, p. 157-239, 1982.

CHEVALLARD, Y. La Transpostion Didactique - du savoir savant au savoir enseigné. Grenoble: La Pensee Sauvage Éditions, 1991.

LANGHI, R. Um estudo exploratório para a inserção da Astronomia na formação de professores dos anos iniciais do Ensino Fundamental. 2004. Dissertação (Mestrado em Educação para a Ciência) - Faculdade de Ciências, UNESP, Bauru.

LEITE, C. Os professores de ciências e suas formas de pensar a Astronomia. 2002. Dissertação (Mestrado em Educação) - Instituto de Física e Faculdade de Educação, Universidade de São Paulo, São Paulo.

LIMA, E. J. M. A visão do professor de ciências sobre as estações do ano. 2006. 119f. Dissertação (mestrado em ensino de ciências e educação matemática) - Universidade Estadual de Londrina, Londrina.

MACIEL, J. W. 25 Anos de Pesquisa em Astrofísica no Brasil. Boletim da Sociedade Astronômica Brasileira, v. 16, n. 2, p. 11-31, 1996.

MATSUURA, O. T. Divulgação da Astronomia: um plano abrangente para o Ensino Básico. In: EXPO ASTRO 1998, SOCIEDADE DE ASTRONOMIA E ASTROFÍSICA DE DIADEMA, E OBSERVATÓRIO MUNICIPAL DE DIADEMA. Anais... Diadema: Sociedade de Astronomia e Astrofísica de Diadema, 1998. p. $5-24$. 
MORAES, R. Tomando conta do ambiente em que se vive: aprendizagem e apropriação de discursos pela linguagem. Revista Abrapec, v. 3, n. 3, set./dez. 2003.

NARDI, R.; ALMEIDA, M. J. P. M. Investigação em Ensino de Ciências no Brasil segundo pesquisadores da área: alguns fatores que lhe deram origem. ProPosições, v. 18, n. 1, p. 52, jan./abr. 2007.

PASSOS, M. M.; NARDI, R.; ARRUDA, S. M. Análises preliminares de revistas da área de Educação Matemática. In: ENCONTRO NACIONAL DE PESQUISA EM EDUCAÇÃO EM CIÊNCIAS, V, 2005, Bauru. Caderno de Resumos.

PASSOS, M. M.; NARDI, R.; ARRUDA, S. M. Primeiras análises de revistas da área de Educação Matemática: a formação do professor em foco. In: SIPEM, III, 2006, Águas de Lindóia. 16p.

PASSOS, M. M.; NARDI, R.; ARRUDA, S. M. 1996-2005: O que foi pesquisado sobre formação de professores? A busca por respostas em revistas da área de Educação Matemática. In: CONGRESSO INTERNACIONAL DE ENSINO DE MATEMÁTICA, IV, 2007, Canoas. Anais... Canoas: Editora da Ulbra, 2007a. v. 1. p. $1-8$.

PASSOS, M. M.; NARDI, R.; ARRUDA, S. M. A pesquisa sobre a formação inicial de professores no Brasil em revistas da área de Educação Matemática. In: ENCONTRO NACIONAL DE PESQUISA EM EDUCAÇÃO EM CIÊNCIAS, VI, 2007, Florianópolis. Caderno de Resumos, 2007b. 12p.

PUZZO, D. Um estudo das concepções alternativas presentes em professores de ciências de $5^{\text {a }}$ série do ensino fundamental sobre fases da lua e eclipses. 2005. 121f. Dissertação (mestrado em ensino de ciências e educação matemática) Universidade Estadual de Londrina, Londrina.

QUEIROZ, V. A Astronomia presente nas séries iniciais do Ensino Fundamental das escolas municipais de Londrina. 2008. 108f. Dissertação (Mestrado em Ensino de Ciências e Educação Matemática) - Universidade Estadual de Londrina, Londrina.

TARDIF, M. Saberes docentes e formação profissional. Petrópolis: Vozes, 2002. $325 \mathrm{p}$. 


\section{Agradecimento}

Agradecemos à professora Marinez Meneghello Passos e ao professor Sergio de Mello Arruda, pelas discussões produtivas na direção da pesquisa. 